\title{
Extraction of Iron (III) with Tributylphosphine Oxide from Hydrochloric \& Sulphuric Acid Solutions
}

\author{
A.V.L.N.S.H. Hariharan \\ Department of Chemistry, GIT, GITAM University. Visakhapatnam - 530 045, India.
}

\section{ABSTRACT}

Solvent extraction of iron (III) from aqueous hydrochloric and sulphuric acid solutions was carried out using Tri butyl phosphine oxide [TBPO] in chloroform as extractant. Stripping of iron (III) from the organic phase was attempted with $2.0 \mathrm{M} \mathrm{NaOH}$. Extractions were nearly quantitative with both the acid solutions. Based on the results obtained, estimation of iron in food samples as well alloys was attempted successfully.

\section{KEYWORDS}

Extraction -iron (III) - Tri capryl amine oxide - Food samples - Iron alloys

\section{INTRODUCTION}

Iron deficiency in human body [anemia] is one of the throughout the course of investigations. Iron content world's most common nutritional deficiency diseases was determined with ELICO SL 191 UV-Visible (Ghadamali et al 2009) and hence the needs for Double beam Spectrophotometer.

analysis of iron in environmental and biomedical materials have been receiving attention. The extraction of iron in its trivalent state from aqueous hydrochloric 2.2 Iron (III) Extraction:

(Sahu,2000; Lee 2005; Staszak et al.2011; Gupta et al An aliquot (10ml) of solution containing iron (III) was 2003) and sulphuric acid (Alguacil,1986) solutions by added with appropriate concentration of the acid in a various extractants has been studied. As there were no separating funnel and $10 \mathrm{ml}$ of $5.2 \times 10^{-2} \mathrm{M}$ of TBPO reports available on the extraction of iron (III) with Tri was added to it. The solution was vigorously shaken butyl phosphine oxide [TBPO], an attempt was made for 10 minutes and the two phases were allowed to on its extraction in hydrochloric as well as sulphuric separate. Iron (III) from the organic phase was stripped 
with $10 \mathrm{ml}$ of $1 \mathrm{M} \mathrm{NaOH}$ and was determined spectrophotometrically (Vogel,1962) at $480 \mathrm{~nm}$ as its colored complex with thiocyanate. The concentration of Iron (III) was computed from the calibration curve.

\section{DISCUSSIONS}

\subsection{Variation of Acidity:}

Iron (III) was extracted with different acid concentrations by $5.2 \times 10^{-2} \mathrm{M}$ TBPO in chloroform and the results are presented in Table-1.It was noticed that the distribution ratio $(\mathrm{Kd})$ increased with increase in concentration of acid up to $9.0 \mathrm{M}(97.46 \%)$ and remained constant in the acidity range $9.0-10.0 \mathrm{M}$ (97.46\% \&98.22\% respectively) from both the acid media followed by decrease in extraction efficiency beyond this acidity. The extractions are nearly quantitative from both the acid solutions employed in the study.

\subsection{Composition of the extracted species:}

The extraction isotherm method (Coleman et.al.,1958) and distribution ratio method (Hesford and Mckay,1958) were employed to determine the composition of the extracted species. In the extraction isotherm method the limiting ratio of the metal to TBPO was found unity under the experimental conditions. Representative data from hydrochloric acid solutions has been provided in Table-2.

\subsection{Effect of TBPO concentration:}

With all other factors being kept constant, iron (III) org. was extracted with $10 \mathrm{ml}$ of TBPO with concentration, varying from $1.0 \times 10^{-2} \mathrm{M}$ to $5.19 \times 10^{-2} \mathrm{M}$. The loglog plots of Kd Vs TBPO from both the acid solutions gave straight lines of with unit slope in hydrochloric acid and two from sulphuric acid media respectively.

\subsection{Effect of diluent:}

Several solvents with varying dielectric constants were tested as the diluents (Table -2). Quantitative extractions were achieved with chloroform as diluent. More than $80 \%$ efficiency was obtained with carbon tetrachloride, benzene, hexane, toluene, cyclohexane \& xylene and much low\% with other diluents. Hence chloroform was preferred as diluent throughout the course of investigations.

\subsection{Effect of various stripping agents:}

After extraction, iron (III) was stripped with $20 \mathrm{ml}$ reagents of various concentrations $(1.0-2.0 \mathrm{M})$ of $\mathrm{HCl}, \mathrm{H}_{2} \mathrm{SO}_{4}, \mathrm{HNO}_{3}, \mathrm{ACOH}$, and $\mathrm{NaOH}$ solutions. It was observed that $2.0 \mathrm{M} \mathrm{NaOH}$ alone is a good stripping agent. However in no case the acid strips out all the iron (III) in a single extraction. 99.8\% iron (III) could be recovered from organic phase by making contact four times with equal volumes of $2.0 \mathrm{M} \mathrm{NaOH}$.

The observed iron: TBPO molar ratio of two from sulphuric acid media and unity from hydrochloric acid solutions (by distribution ratio method) could be explained as arising from the extraction of iron (III) by the following solvation mechanism.:

From hydrochloric acid solutions:

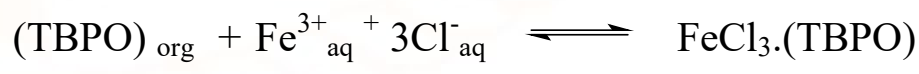


from sulphuric acid solutions: 4 CONCLUSION

2 (TBPO) org $+2 \mathrm{Fe}^{3+} \mathrm{aq}+3 \mathrm{SO}_{4}{ }^{2-}$ aq $\rightleftharpoons$ The proposed method is simple, rapid and selective. It

$\left[\mathrm{Fe}_{2}\left(\mathrm{SO}_{4}\right)_{3}\right]$. 2(TBPO) $)_{\text {org. }}$

takes less than half an hour to extract and determine

On the basis of the proposed mechanism for the iron content in alloys with accuracy.

extraction of iron (III), the dependence of the distribution ratio on the nature of the mineral acid was well under stood.

\section{ACKNOWLEDGEMENTS}

Thanks are due to University grants Commission, New Delhi for financial assistance. Thanks are also due to 3.6 Analysis of iron in samples:

Principal, GIT and Management of GITAM University

The validity of the method of extraction for recovery for providing necessary facilities.

of iron has been tested by analyzing iron content in alloys. A known weight $(1.0 \mathrm{gm})$ of the finely powdered sample was dissolved in aquaregia. The solution was evaporated and extracted with dilute hydrochloric acid solution. The mixture was shaken well for about $15 \mathrm{~min}$. Then the mixture was diluted by $0.01 \mathrm{M} \mathrm{HCl}$ solution to the mark and then filtered by Whatmann filter paper No. 40. The first portion of filtrate was discarded.

The clear solution so obtained was made up to $100 \mathrm{ml}$ and used as stocksolution.10ml of this iron solution was shaken for five minutes with an equal volume of $5.0 \times 10^{-2} \mathrm{M}$ of TBPO. After separation of two phases, Iron (III) from the organic phase was stripped with 10 $\mathrm{ml}$ of $2.0 \mathrm{M} \mathrm{NaOH}$ and was determined spectrophotometrically as described earlier. Results are presented in Tables $-3 \& 4$. 


\section{RESULTS}

Table 1: variation of Acidity on Extraction

$[\mathrm{Fe}(\mathrm{III})]=1.2 \times 10^{-3} \mathrm{M}$

$[\mathrm{TBPO}]=5.2 \times 10^{-2} \mathrm{M}$
Table 2: Effect of diluent on extraction ( $\mathrm{H}_{2} \mathrm{SO}_{4}$ medium)

$$
[\mathrm{Fe}(\mathrm{III})]=1.2 \times 10^{-3} \mathrm{M}
$$$$
\mathrm{pH}=9.0
$$

$[\mathrm{TBPO}]=5.2 \times 10^{-2} \mathrm{M}$

\begin{tabular}{|l|c|c|}
\hline \multicolumn{1}{|c|}{ Diluent } & $\begin{array}{c}\text { Dielectric } \\
\text { constant }\end{array}$ & $\begin{array}{c}\% \\
\text { extraction }\end{array}$ \\
\hline $\mathrm{CHCl}_{3}$ & 2.28 & 98.22 \\
\hline $\mathrm{CCl}_{4}$ & 2.23 & 88.81 \\
\hline Benzene & 4.81 & 83.35 \\
\hline Cyclo hexane & 2.00 & 80.67 \\
\hline n-Hexane & 1.89 & 82.37 \\
\hline n-heptane & 1.92 & 76.75 \\
\hline Nitrobenzene & 34.82 & 69.42 \\
\hline Toulene & 2.43 & 82.84 \\
\hline Xylene & 2.56 & 84.15 \\
\hline
\end{tabular}

\begin{tabular}{|c|c|c|}
\hline $\begin{array}{c}\text { Molarity } \\
(\mathrm{M})\end{array}$ & $\begin{array}{c}\text { \%Extraction } \\
(\mathrm{HCl})\end{array}$ & $\begin{array}{c}\text { \%Extraction } \\
\left(\mathrm{H}_{2} \mathrm{SO}_{4}\right)\end{array}$ \\
\hline 1.0 & 52.92 & 57.92 \\
\hline 2.0 & 72.48 & 63.25 \\
\hline 3.0 & 90.24 & 62.50 \\
\hline 4.0 & 92.08 & 74.62 \\
\hline 5.0 & 95.19 & 88.24 \\
\hline 6.0 & 96.42 & 89.76 \\
\hline 7.0 & 97.05 & 91.28 \\
\hline 8.0 & 97.18 & 98.02 \\
\hline 9.0 & 97.46 & 98.22 \\
\hline 10.0 & 97.46 & 98.22 \\
\hline 11.0 & 92.28 & 94.89 \\
\hline 12.0 & 81.37 & 86.75 \\
\hline
\end{tabular}




\section{Table -3: Determination of Iron in Alloys}

\begin{tabular}{|c|c|c|c|c|c|c|c|c|c|}
\hline Material & Carbon & Manganese & Sulfur & Phosphorus & Silicon & Iron & $\begin{array}{c}\text { mount } \\
\text { of } \\
\text { Iron(III) } \\
\text { taken } \\
\text { (ppm) }\end{array}$ & $\begin{array}{l}\text { Amount } \\
\text { of } \\
\text { Iron(III) } \\
\text { found } \\
\text { (ppm) }\end{array}$ & $\begin{array}{c}\% \\
\text { Recovery }\end{array}$ \\
\hline $\begin{array}{l}\text { Cast } \\
\text { Iron }\end{array}$ & 3.430 & 0.880 & 0.041 & ---- & 2.120 & $91-91.2$ & 90.5 & 90.25 & 99.56 \\
\hline $\begin{array}{c}\text { Carbon } \\
\text { steel }\end{array}$ & $\begin{array}{c}0.007- \\
1.3\end{array}$ & $0.3-1.0$ & $\begin{array}{c}0.02- \\
0.06\end{array}$ & $0.002-0.1$ & $\begin{array}{c}0.005- \\
0.5\end{array}$ & $98.1-99.5$ & 95.5 & 95.82 & 99.30 \\
\hline $\begin{array}{c}\text { Wrought } \\
\text { iron }\end{array}$ & $\begin{array}{l}0.05- \\
0.25\end{array}$ & $0.01-0.1$ & $0.02-0.1$ & $0.05-0.2$ & $0.02-0.2$ & $99-99.8$ & 97.5 & 97.33 & 99.59 \\
\hline
\end{tabular}

\section{REFERENCES}

1. Ghadamali ,B .MansourA.C, .Zeinab,B., (2009)

Eurasian J. Anal. Chem., ,4(3), 285-293

2. Sahu,KK and Das, RP (2000) Metlrgy. Met. Trans.B, 2000, 31(B), 1169.

3. Lee,MS K.J. Lee ,KJ (2005) Hydrometallurgy, 2005,80, 163.

4. Staszak,K .Clerpiszewski,R K. Prochaska,K,(2011) Polish J. Chem. Tech., 1(1), 1-5.

5. Gupta,B..Deep,A..Singh AVand Tandon,SN . Hydrometallurgy, 2003 70, 121.

6. F.JAlguacil, S. Amer (1986) Polyhedron, 6(11), 1755.

7. J.Kennedy ,R.Perkins(1964) J. Inorg .Nucl .Chem., 26, 1601.
8. Vogel, A.I(1962), (3rd Edn), A Text book of quantitative Inorganic Analysis, Longman, London

9. C.F. Coleman,K.B. Brown, J.G.Moore., K.A.Allen,(1958) Proc.2nd Intl. Conf., Peaceful Uses of Atomic Energy, Geneva, C. 10,510 .

10. E.Hesford.E. H.A.C Mckay, (1958) Trans Faraday Soc., 54, 573 